\title{
A Velhice e a Morte: reflexões sobre o processo de luto
}

\section{OdAgeandDeath: thangtsabat thegrief process}

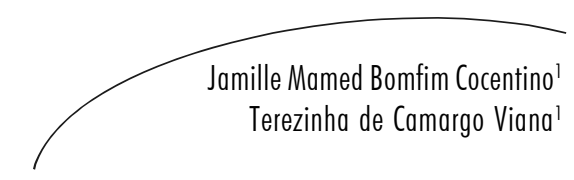

Resumo

Neste trabalho, apresentamos e discutimos, sob a perspectiva da psicanálise, reflexões sobre a associação da morte com o processo de envelhecimento humano. São analisadas, inicialmente, elaborações freudianas sobre a morte na cultura, destacando o estranhamento e o desamparo perante a velhice e a morte. Reflexões sobre a vivência da morte nas perdas experienciadas na velhice são apresentadas neste trabalho, que também propõe uma discussão acerca do luto que é vivido simbolicamente nas perdas associadas ao processo de envelhecimento. As perdas vividas na velhice estão relacionadas à morte real de amigos e companheiros, ao corpo, ao fim das relações de trabalho, ao relacionamento social e familiar. Tais perdas perpassam tanto a dimensão do físico, em sua concretude, como os universos profissional, social e familiar. Após uma análise bibliográfica, concluímos que é pertinente a reflexão de que a morte e a velhice constituem fenômenos fortemente atrelados na cultura, de modo que uma abordagem sobre o envelhecimento parece demandar uma compreensão e discussão do processo de luto vivenciado nas sucessivas experiências de perdas na velhice.

\section{Abstract}

This paper presents and discusses, under a psychoanalytic perspective, some thoughts about the association of death with the human aging process. Firstly, Freudian concerns about death in culture are analyzed, with regard mainly to the strangeness and helplessness about elderly and death. A debate about the death in losses experienced in old age takes place in this work, which also proposes a discussion about grief symbolically lived in losses associated with the aging process. The losses lived in old age are related to the real death of friends and colleagues, to the body, to the end of work relations, and to social and family relationships. Such losses persist beyond the physical dimension, in a concrete

Palavras-chave:

Envelhecimento. Morte. Relação familiar. Idoso. Perdas. Luto. Psicanálise. 
sense, and also beyond the social, family and professional realms. After a bibliographic analysis, we conclude that the reflection about death and old age as a phenomenon strongly related to culture is pertinent and relevant. Therefore, an academic approach to the issue of human aging seems to demand a comprehension and discussion of the grief process lived in the successive experiences of losses in old age.
Key words: Aging. Death. Family Relations. Aged. Losses. Grief. Psychoanalysis.

\section{INTRODUÇÃOO}

Neste trabalho apresentamos e discutimos, sob a perspectiva da psicanálise, reflexões sobre a associação da morte com o processo de envelhecimento humano. Analisamos, inicialmente, elaborações freudianas sobre a morte na cultura, destacando o estranhamento e o desamparo perante a velhice e a morte. Reflexões sobre a vivência da morte nas perdas experienciadas na velhice são apresentadas neste trabalho, que também propõe uma discussão acerca do luto que é vivido simbolicamente nas perdas associadas ao processo de envelhecimento.

As perdas vividas na velhice estão relacionadas à morte real de amigos e companheiros, ao corpo, ao fim das relações de trabalho, ao relacionamento social e familiar. Tais perdas perpassam tanto a dimensão do físico, em sua concretude, como os universos profissional, social e familiar. São vivenciadas, muitas vezes, concomitantemente. Carvalho \& Coelho ${ }^{1}$ sustentam que uma implicação do envelhecimento é o enfrentamento de sucessivas perdas reais e simbólicas. É possível, também, a constatação de que o enfrentamento de uma perda pode acelerar e potencializar a vivência de outras perdas.

\section{Estranhamento e desamparo perante a velhice e a morte}

Em O futuro de uma ilusão, Freud $^{2}$ sustenta que a natureza se impõe ao homem a despeito do esforço civilizatório dispensado pelos humanos visando à esquiva e à fuga da fraqueza e do desamparo. A morte, argumenta Freud, constitui uma questão obscura para o homem e que não pode ser remediada e vencida. Ela, provavelmente, permanecerá um enigma irremediável para sempre. O fenômeno da morte demonstra, portanto, a grande e imponente força da natureza sobre os homens e expõe os limites da condição humana:

Há os elementos, que parecem escarnecer de qualquer controle humano; a terra, que treme, se escancara e sepulta toda a vida humana e suas obras; a água, que inunda e afoga tudo num torvelinho; as tempestades, que arrastam tudo o que lhes antepõe, as doenças, que só recentemente identificamos como sendo ataques oriundos de outros organismos, e, finalmente, o penoso enigma da morte, contra o qual remédio algum foi encontrado e provavelmente nunca será. É com essas forças, que a natureza se ergue contra nós, majestosa, cruel e inexorável; uma vez mais nos traz à mente nossa fraqueza e desamparo, de que pensávamos ter fugido através do trabalho de civilização (Freud ${ }^{2}$, 1928/2006, p. 25).

Apesar de avanços e conquistas do processo civilizatório, constituído também pelos conhecimentos e habilidades desenvolvidas pelo homem para manter sob controle as forças naturais e possibilitar a satisfação de necessidades humanas, as forças da natureza muitas vezes se sobrepõem às forças do homem. A morte, nesse contexto, escancara as limitações do homem frente à grandiosidade da natureza e constitui um fenômeno que o homem se esquiva por meio da constituição da civilização. Ademais, o homem costuma denominar os prejuízos provocados pela natureza incontrolável de "Destino" (Freud ${ }^{2}, 1928$ / 2006). A morte pode ser, portanto, significada como um "Destino" imperioso para o ser humano.

A morte não costuma ser vista como algo espontâneo e natural pelas pessoas. Ela é, 
constantemente, atribuída a um ato externo e brutal oriundo de uma Vontade maligna. $\mathrm{O}$ homem, para lidar e suportar a imponência da morte, com a ansiedade provocada por esse fenômeno, recorre, através de meios psíquicos, a explicações sobre o sobrenatural. A natureza é, então, humanizada na medida em que suas forças são atribuídas a seres como os humanos, permitindo às pessoas a não paralisação causada pelo desamparo. Assim, por meio das ideias e crenças religiosas, o homem encontra subsídios para reagir às forças da natureza, embora ainda se encontre indefeso frente à morte. As ideias e crenças religiosas nascem da necessidade que o homem tem de tornar seu desamparo suportável. Os fenômenos da natureza foram melhor compreendidos com o tempo e, com isso, às forças naturais atribuíram-se menos traços humanos (Freud $\left.{ }^{2}, 1928 / 2006\right)$ :

O desamparo do homem, porém, permanece e, junto com ele, seu anseio pelo pai e pelos deuses. Estes mantêm sua tríplice missão: exorcizar os terrores da natureza, reconciliar os homens com a crueldade do "Destino", particularmente a que é demonstrada na morte, e compensá-los pelos sofrimentos e privações que uma vida civilizada em comum lhes impôs (Freud², 1928/2006, p.26).

Nesse sentido, constatamos que embora o homem tenha conquistado uma maior compreensão dos fenômenos naturais, o desamparo e o anseio pelo pai e pelos deuses se mantêm. Assim, os deuses têm a função de permitir que o desamparo possa ser suportável para o homem.

Laplanche \& Pontalis $^{3}$ esclarecem que desamparo constitui um termo da linguagem comum que revela especificidades na teoria freudiana. $\mathrm{O}$ estado de desamparo constitui o estado do lactente que depende completamente de um outro para a satisfação de suas necessidades, tais como fome e sede. Trata-se, segundo os autores, de um estado necessário para que a tensão interna possa ser finalizada, por meio da realização de uma ação específica e adequada.

O estado de desamparo constitui para o homem adulto o protótipo da situação traumática geradora de angústia, na medida em que a perda ou a separação levam a uma elevação da tensão podendo, inclusive, em casos extremos, o sujeito se ver incapaz de dominar suas excitações e ser submergido por elas, o que pode delinear e gerar o sentimento de desamparo. Podemos pensar, portanto, a busca do homem pela religião também como uma forma constituída na civilização de fuga do desamparo marcadamente evidenciado no fenômeno da morte. A busca pelos deuses e por um maior controle e entendimento do "Destino" pode ser refletida como uma forma de fuga do desamparo e fragilidade do homem (Laplanche \& Pontalis ${ }^{3}$, 2004).

Freud $^{4}$ entende como religião o sistema de doutrinas e promessas que se propõe a explicar de forma invejável os fenômenos enigmáticos do mundo. A religião, segundo o autor, assegura uma Providência que olhará pela vida dos homens, compensando-lhes pelas frustrações vividas em uma existência futura. Diante disso, constatamos uma forte associação da morte com a religião, observável em diferentes culturas. São fenômenos intricados no imaginário socialmente construído e que perpassam o tecido cultural. É nesse contexto que as subjetividades individuais são construídas, ao passo que constroem o imaginário compartilhado na sociedade.

Elisabeth Kübler-Ross ${ }^{5}$ defende que a morte é frequentemente imaginada como um acontecimento medonho e pavoroso na sociedade, constituindo um temor compartilhado por todos. Assim, os homens parecem se esquivar da morte ou até mesmo ignorá-la, de forma que o homem parece negar a própria condição de ser mortal.

A respeito da percepção do homem sobre a morte, Loureiro ${ }^{6}$, em $A$ velhice, o tempo e a morte, esclarece que, apesar de o ser humano se reconhecer como finito, ou seja, mortal, "no fundo está convencido da própria imortalidade" (p.77). Assim, embora "traumatizados" pela morte e pela perda de pessoas queridas, os homens vivem como se nunca fossem realmente morrer. Ademais, Kübler-Ross ${ }^{5}$ sustenta que a morte é com frequência representada socialmente como um 
tabu, uma questão considerada mórbida e proibida:

Recorremos aos eufemismos; fazemos com que o morto pareça adormecido; mandamos que as crianças saiam, para protegê-las da ansiedade e do tumulto reinantes na casa, isto quando o paciente tem a felicidade de morrer em seu lar; impedimos que as crianças visitem seus pais que se encontram a beira $\mathrm{da}$ morte nos hospitais; sustentamos discussões longas e controvertidas sobre dizer ou não a verdade ao paciente (Kübler-Ross ${ }^{5}$, 1998, p.11).

A referida autora argumenta que em diferentes épocas e culturas esse fenômeno de relutância à percepção da morte pode ser constatado de forma que, frequentemente, a morte é repelida e rechaçada na sociedade. É possível explicar o referido fenômeno, argumenta, pela constatação de que, no inconsciente, a morte é impossível para o próprio sujeito. Ademais, demonstra que, para o inconsciente humano, a finitude da vida é atribuída a algo maligno que está fora do alcance dos homens, de forma que "em nosso inconsciente só podemos ser mortos; é inconcebível morrer por causa natural ou idade avançada" (KüblerRoss ${ }^{5}, 1998$, p.6).

$\mathrm{Fuks}^{7}$, no livro Frende a cultura, esclarece que é pelo reconhecimento da morte de um outro que o sujeito se dá conta da própria finitude. Dessa forma, a morte se configura para o homem como uma realidade para os outros e não para o próprio sujeito.

Simone de Beauvoir ${ }^{8}$ relata que, quando esteve gravemente doente pela primeira vez na vida, precisou repetir espantada para si mesma: "Sou eu a mulher que estão levando nesta maca” (1976, p.7). Constata que um fenômeno esperado para todos não é visto pelo sujeito, muitas vezes, como previsível para si mesmo.

A concepção de mortalidade dos pais costuma, também, ser negada e abstraída com frequência pelos filhos, uma vez que pode suscitar sentimentos de desamparo e fraqueza nos mesmos. Igualmente, o declínio das funções orgânicas advindo com o envelhecimento é negado e evitado com frequência pelos filhos por estar associado à finitude da vida. Salvarezza ${ }^{9}$ destaca que os filhos muitas vezes se negam a aceitar as limitações físicas consequentes do processo de envelhecimento em seus pais da mesma forma que tendem a negar o adoecimento dos mesmos.

Salvarezza ${ }^{9}$ esclarece ainda que, como na espécie humana os filhos nascem extremamente indefesos, são imprescindíveis figuras, comumente os progenitores, que assegurem a sobrevivência tanto do indivíduo quanto da espécie humana por meio de uma intervenção ativa. Aos pais, em contrapartida, são atribuídas pelos filhos características reais e, também, fantasmáticas de grande importância. Assim, aos pais são investidas características idealizadas de onipotência, de acordo com os desejos e necessidades dos filhos. Esse é um importante e pertinente motivo pelo qual os filhos apresentam, com frequência, dificuldade tanto em prever o declínio físico dos pais quanto em aceitá-lo. A constatação da velhice ou da enfermidade pode levar os filhos a se sentirem tão indefesos como na infância, fazendo com que grande ansiedade seja vivida. Os filhos, segundo Salvarezza ${ }^{9}$, resistem a constatar a velhice de seus pais e, quando algum acontecimento a evidencia, muitas dificuldades e conflitos podem surgir.

Bromberg $^{10}$ argumenta que em diferentes culturas é possível identificar o mito da imortalidade. Ele é constatado ora por meio do entendimento de crenças ou ritos, ora de forma simbólica. Simbolicamente, o desejo de imortalidade encontra expressão mediante a descendência deixada pelo sujeito que garante simbolicamente sua perpetuação. Ainda a noção de imortalidade da alma ou, também, a produção criativa, são formas simbólicas de garantia de eternidade. Podemos pensar, ainda, que os diversos rituais para manutenção da juventude são reconfigurações dessa mesma construção mítica. $\mathrm{O}$ aparente adiamento da velhice pode parecer protelar igualmente o confronto com a morte que está social e culturalmente atrelada à velhice desde a antiguidade.

A esse respeito, Néri ${ }^{11}$ destaca que o envelhecimento se refere a um processo. A 
velhice é uma fase da vida. Os idosos, por sua vez, são os indivíduos designados assim a partir de critérios socialmente construídos. Segundo Beauvoir ${ }^{8}$, a velhice, assim como a morte, costuma parecer uma realidade distante para o homem. Dessa forma, a velhice e a morte ganham um caráter abstrato para o indivíduo por certo tempo. Nessa direção, cita Proust: "Talvez seja (a velhice) dentre todas as realidades, aquela cuja noção puramente abstrata mantemos durante maior lapso de tempo" (Beauvoir $^{8}, 1976$, p.8).

Para a autora, os homens tendem a lembrar e refletir sobre a própria mortalidade com maior facilidade e constância que do próprio processo de envelhecimento, uma vez que a morte é uma possibilidade em todas as idades. A morte parece, portanto, ser frequentemente imaginada com maior lucidez e nitidez do que a velhice pelos homens. Já a velhice configura-se subjetivamente como uma possibilidade longínqua e distante para os mesmos.

Beauvoir ressalta que embora a velhice racionalmente devesse ser esperada e previsível para todos, constitui um fenômeno muitas vezes constatado com espanto pelo sujeito que envelhece, chegando o adulto a comportar-se como se nunca pudesse envelhecer. Nesse sentido, refere-se a Goethe: "A idade se apodera de nós de surpresa” (Beauvoir", 1976, p.7). Sustenta, assim, que a velhice constitui um destino que deixa as pessoas estupefatas quando acontece na vida delas.

A velhice se constitui para o sujeito por meio do olhar do outro, sustenta Beauvoir. Ou seja, para a autora, o sujeito se conscientiza da própria velhice através do olhar que o outro lhe devolve: "A velhice aparece com maior clareza aos olhos dos outros que aos do próprio sujeito; é um novo estado de equilíbrio biológico: quando a adaptação se opera sem choques, o indivíduo não se dá conta do envelhecimento" (Beauvoir ${ }^{8}$ 1976, p.8). Nesse sentido, características do envelhecimento podem ser confundidas como uma disfunção física passageira pelo sujeito e é o outro que muitas vezes aponta ao sujeito sua velhice:
A percepção da velhice normalmente acontece de "fora para dentro", ela vem de fora, por parte de outra pessoa, de um espelho ou de alguma situação presente no cotidiano. Estamos falando que a velhice não é reconhecida pela própria pessoa de imediato, ela é algo do externo, tanto que os psicanalistas falam do "susto ao espelho" como um momento de surpresa e não reconhecimento frente à própria imagem (Barbieri ${ }^{12}$, 2003, p.21).

O reconhecimento da própria velhice pelo sujeito costuma envolver um olhar devolvido pelo mundo externo à pessoa, seja o olhar de uma outra pessoa, do espelho ou de algum elemento do dia a dia. A velhice, embora seja racionalmente esperada e previsível, é com frequência percebida pelo sujeito que envelhece com surpresa ou, até mesmo, com espanto. Essa percepção da própria velhice envolve um olhar devolvido por um outro externo ao sujeito.

Segundo Mucida ${ }^{13}$, a velhice pode ser entendida também como uma fase do desenvolvimento humano em que a ideação da própria morte costuma se aproximar do sujeito que envelhece e ganhar nitidez. Uma vez que o sujeito vivencia as perdas relacionadas ao processo de envelhecimento e as mudanças igualmente vivenciadas no corpo com o avançar da idade, o processo de luto é comumente experimentado. Assim, o fantasma da infinitude parece esvanecer e a morte se aproxima do sujeito que envelhece:

A velhice pode ser também o momento em que o fantasma da infinitude escancara sua face não mais tão divertida por diferentes perdas e modificações corporais, encontrando, ainda, uma certa fragilização dos recursos simbólicos. Tudo isso impõe o trabalho de luto [...]. O prelúdio da morte anunciada poderá igualar-se à velhice (Mucida ${ }^{13}, 2006$, p.144).

Nessa direção, Picabia \& Antequera-Jurado ${ }^{14}$, em La muerte y el morir en el anciano, destacam que embora o homem não perceba a própria morte como um fenômeno normal, a morte do idoso parece ser a mais facilmente aceita e tolerada na sociedade. Assim, destacam que a morte na velhice é frequentemente percebida com maior 
naturalidade pelas pessoas do que a morte em outras fases da vida. Ademais, os idosos costumam ter experimentado maior contato com pessoas que já morreram do que os mais jovens e, portanto, parecem apresentar uma melhor percepção da própria morte como algo possível e até mesmo iminente quando comparados com grupos etários mais jovens.

Podemos, portanto, constatar uma marcante associação simbólica da velhice com a morte para homem. A morte é vivida simbolicamente nas perdas que são vividas ao longo do envelhecimento. O trabalho de luto é uma consequência da morte simbólica vivenciada nas perdas do envelhecimento.

\section{Perdas na velhice e luto simbólico}

Acreditamos que a morte é vivida simbolicamente nas perdas vivenciadas na velhice. Ao lidar com essas perdas, o idoso lida inevitavelmente com a morte, e vivencia o processo de luto. Envelhecimento e morte estão simbolicamente atrelados, de maneira marcante, na sociedade e na cultura. Dessa forma, nos parece que a compreensão sobre como essas perdas relacionadas à velhice são vividas está intimamente intricada ao entendimento do processo de luto.

No texto Luto e melancolia, Freud ${ }^{15}$ nos ensina que "o luto, de modo geral, é a reação à perda de um ente querido, à perda de alguma abstração que ocupou o lugar de um ente querido, como o país, a liberdade ou o ideal de alguém, e assim por diante" (1915/2006, p.249). A consciência da perda que é real está presente no luto, havendo, ainda, um esvaziamento do mundo exterior uma vez que as energias do ego são absorvidas durante todo o processo de luto:

O luto ocorre sob a influência do teste de realidade, pois a segunda função exige categoricamente da pessoa desolada que ela própria deva separar-se do objeto, visto que ele não mais existe. Ao luto é confiada a tarefa de efetuar essa retirada do objeto em todas aquelas situações nas quais ele foi o recipiente de elevado grau de catexia. Que essa função deva ser dolorosa ajusta-se ao que acabamos de dizer, em vista da catexia de anseio, elevada e não passível de satisfação, que está concentrada no objeto pela pessoa desolada durante a reprodução das situações nas quais ela deve desfazer os laços que a ligam a ele (Freud ${ }^{16}, 1925 / 2006$, p.167).

Freud $^{16}$, no texto Ansiedade, dor eluto, define que a dor constitui a reação real à perda de objeto e representa um sentimento de desprazer com caráter específico de dor. Trata-se de um caráter que, segundo o autor, não pode ser descrito com maior precisão. Quando a catexia de anseio - que está concentrada no objeto do qual se sente falta ou que está perdido - cria as condições econômicas oriundas pela catexia de dor - que se encontra concentrada em uma parte danificada do corpo, no caso da dor física - surge a sensação de dor na esfera mental. O processo de luto é, portanto, frequentemente permeado de dor, sendo constantemente penoso para o sujeito que o vivencia.

O objeto perdido na velhice, no tocante às perdas orgânicas, pode ser, por exemplo, a acuidade visual e auditiva, o vigor físico, a beleza juvenil - extremamente valorizada na sociedade ocidental, a memória, a elasticidade e a potência sexual. Também o status alcançado por meio do desenvolvimento da atividade profissional, o convívio constante com colegas de trabalho e ainda a redução de proventos constituem possíveis objetos perdidos na aposentadoria. Ainda, a mudança de papel e status na vida em família e a perda do par amoroso e de amigos podem desencadear o processo de luto nessa fase do desenvolvimento do homem. Trata-se de perdas verdadeiramente experimentadas e o sujeito que envelhece costuma ter consciência das mesmas.

A morte está, dessa forma, intensamente presente nas transformações que o envelhecimento impõe ao homem. Essa presença se dá no real, mas, também, na esfera simbólica. Ela culmina no processo de luto. O luto, por sua vez, é resultado da perda de um objeto amado, conforme demonstram Arraes \& Viana ${ }^{17}$ :

Freud revela que o luto diz respeito à perda de um objeto de investimento pulsional que não é necessariamente um ser humano. 
Temos, então, que a noção de luto como afeto se faz a partir de uma perspectiva descritiva em que se leva em consideração o impacto ou ressonância emocional que a perda de alguém ou algo querido pode provocar na vida libidinal. O luto seria o afeto que tem sua expressão provocada pelo impacto da perda.

O luto pode ser entendido, assim, como um afeto que é provocado pelo impacto da perda de um objeto de investimento libidinal. Esse objeto não precisa ser necessariamente, um ser humano. Nesse contexto, Freud ${ }^{15}$ esclarece que oluto é caracterizado por uma falta de ânimo dolorosa, perda de interesse pelo mundo externo, perda da capacidade de amar e limitação de atividades, havendo, portanto, uma inibição egóica (Freud ${ }^{15}, 1915 / 2006$ ).

Arraes \& Viana ${ }^{18}$ explicam a dimensão de dor envolvida no processo de luto da seguinte forma: "A dor do luto pode ser entendida, então, como a dor de ter de, em certa medida, 'desamar' o objeto perdido e 'amar' outros objetos, de ter de abandonar uma posição libidinal e criar uma outra”.

Quando a realidade demonstra a supressão do objeto amado, a libido precisa ser redirecionada para outros objetos. No entanto, Freud nos adverte que se trata de um processo bastante doloroso que demanda tempo e energia catexial para encontrar seu desfecho. Ademais, o processo de luto estende a existência do objeto perdido por certo tempo. Quando é concluído, a energia libidinal fica novamente livre, podendo, então, ser reinvestida. Dessa forma, o objeto perdido pode ser substituído (Freud $\left.{ }^{15}, 1915 / 2006\right)$. Entendemos, então, que o luto é um processo intensamente perpassado pela dor que é consequência da perda real de um objeto de grande investimento libidinal:

O luto é um afeto que resulta do desligamento ou desinvestimento de certa quantidade de energia (quantum de afeto) que antes era dirigida ao objeto perdido. Assim, independentemente da natureza do objeto perdido, tal quantidade de energia vai assumir uma expressão subjetiva de luto. Com a perda do objeto amado, o quantum de afeto tem de se destacar do objeto por meio do "trabalho de luto" (Arraes e Viana ${ }^{17}, 2003$, p.13).
Com a perda do objeto de investimento libidinal, há o desligamento ou desinvestimento de energia anteriormente dirigida ao objeto que foi perdido. O luto refere-se ao afeto que resulta desse processo. Para Freud ${ }^{15}$, o luto refere-se, ademais, a uma reação natural, ou seja, a uma reação esperada diante da perda de um objeto amado. Dessa forma, não pode ser sempre entendido como um processo patológico, mas como uma condição que deverá ser superada com o tempo.

Arraes $\&$ Viana $^{17}$ analisam que, em diferentes produções freudianas, o luto é caracterizado como afeto normal ou, ainda, como estado afetivo. $\mathrm{Ou}$ seja, como presente na natureza humana, sendo, inclusive, previsível e superado com o tempo. Assim, as dores e cicatrizes do processo de luto são curadas e superadas naturalmente com o tempo sem que sejam necessárias intervenções terapêuticas específicas.

Mucida ${ }^{13}$ destaca que o medo da morte, muito presente na cultura, está associado ao temor da perda do investimento libidinal. Assim, na velhice ou em diferentes fases da vida em que o temor da morte é constatado, o sujeito desinveste libidinalmente do mundo. A referida autora argumenta que a morte do desejo, isto sim, constitui o grande temor na velhice. A morte não é conhecida para o inconsciente humano de forma que é o medo da perda do desejo, que parece estar mais presente na velhice:

A velhice nos traz o desamparo de forma incisiva. Teme-se na velhice, já o dissemos, não a morte, já que o inconsciente a desconhece, mas outra morte que escutamos na clínica - a morte do desejo, a exposição do gozo. Todavia, isso não pode ser associado simplesmente à velhice; o desejo não se mede pela idade cronológica, pela idade de nossos vasos sanguíneos, artérias, ossos ou coração, mas sustenta-se por nossa relação como os objetos, à medida que podemos agalmatizá-los (Mucida ${ }^{13}, 2006$, p.146).

As perdas vividas na velhice parecem evidenciar a condição de desamparo do homem e a morte do desejo pode vir a ser temida quando o sujeito vivencia sucessivamente o trabalho de luto. A 
morte real não é conhecida pelo inconsciente, mas as perdas de investimento libidinal associadas ao envelhecimento parecem associar a velhice à morte de forma simbólica.

No entanto, Mucida ${ }^{13}$ adverte que o desejo não está associado à idade cronológica. A idade avançada não constitui, portanto, uma limitação para o desejo humano. A autora sustenta ainda que, apesar de o homem viver diversas perdas ao longo de sua vida, em diferentes fases do desenvolvimento humano, é notável que com o avançar dos anos essas perdas tendem a ser vividas com frequência mais elevada. As perdas vivenciadas ao decorrer do processo de envelhecimento levam ao trabalho de luto:

As perdas advindas com o envelhecimento/ velhice exigem sempre um trabalho de luto, pois é um momento no qual muitos rearranjos que o sujeito teceu para enfrentar o real desmoronam e com eles muitos dos ideais. Não podemos negar que, apesar de vivenciarmos perdas durante toda a vida, estas são mais frequentes a partir de certa idade - variável para cada um - impondo elaborações para a construção de outros ideais (Mucida ${ }^{13}$, 2006, p.155).

No texto Sobre a transitoriedade, Freud ${ }^{19}$ nos diz que "A beleza da forma e da face humana desaparece para sempre no decorrer de nossas próprias vidas; sua evanescência, porém, apenas lhe empresta renovado encanto" (1916/2006, p.317). Sustenta, dessa forma, que a transitoriedade das coisas aumenta, potencializa o valor das mesmas para o homem. Assim, o caráter transitório de alguns atributos característicos da juventude como a força física e a beleza juvenil, por exemplo, parece exacerbar o valor desses atributos, conforme ilustra:

O valor da transitoriedade é o valor da escassez no tempo. A limitação da possibilidade de uma fruição eleva o valor dessa fruição. Era incompreensível, declarei, que o pensamento sobre a transitoriedade da beleza interferisse na alegria que dela derivamos (Freud ${ }^{19}, 1916 / 2006$, p.317).

Freud nos alerta, contudo, que a compreensão da transitoriedade do belo pode levar a um processo de luto antecipatório, que é uma forma de defesa psíquica que compromete o desfrute da beleza. Assim, ocorre uma desistência permanente da possibilidade de desfrute proporcionada por um objeto por sua efemeridade. O luto chega a um fim, contudo, de forma natural. Quando isso acontece, a libido volta a se libertar e pode, então, investir em novos objetos, substituindo o que foi perdido. Esse novo objeto terá o valor do que foi perdido ou, talvez, um valor ainda maior.

Segundo Freud ${ }^{19}$, a "exigência de imortalidade" que pode ser consequência da consciência da transitoriedade da vida é fruto de nossos desejos. Ou seja, não se refere à ordem da realidade e sim à ordem do desejo. Assim, por mais difícil e árdua que possa se configurar a noção de transitoriedade da vida, trata-se de uma concepção profundamente verdadeira e que exerce influência sobre o valor do objeto para o sujeito.

Frumi \& Celich $^{20}$, no artigo O olhardo idoso frente ao envelhecimento e a morte, defendem a importância de diálogos que abordem o processo de envelhecimento e a morte. Argumentam que essa discussão possibilita um maior entendimento da complexidade do homem em suas dimensões sociais, culturais, psicológicas e espirituais. Demonstram, portanto, a necessidade de que a morte e a velhice sejam abordadas sob uma ótica que considere aspectos muitas vezes considerados proibidos e difíceis na sociedade por meio de uma discussão ampla e que envolva diferentes áreas de construção do conhecimento. Para as autoras, uma abordagem complexa sobre a velhice e as perdas na velhice pode possibilitar a promoção de qualidade de vida.

\section{CONCLUSÃO}

Diante do acima exposto, constatamos ser pertinente a reflexão de que a morte e a velhice constituem fenômenos fortemente atrelados na cultura, de modo que uma abordagem sobre o envelhecimento parece demandar uma compreensão e discussão do processo de luto vivenciado nas sucessivas experiências de perdas na velhice. 


\section{REFERÊNCIAS}

1. Carvalho IS, Coelho VLD. Mulheres na maturidade e queixa depressiva: compartilhando histórias, revendo desafios. Psico 2006 jan/jun; 11 (1): 113 - 122.

2. Freud S. O futuro de uma ilusão: o mal-estar na civilização e outros trabalhos 1927-1931. Rio de Janeiro: Imago; 1928/2006. v.21

3. Laplanche J, Pontalis JB. Vocabulário de psicanálise. São Paulo: Martins Fontes; 2004.

4. Freud S. O mal-estar na civilização : o futuro de uma ilusão, o mal-estar na civilização e outros trabalhos 1927-1931. Rio de Janeiro: Imago; 1929/2006. v.21

5. Kubler-Ross E. Sobre a morte e o morrer: o que os doentes terminais têm para ensinar a médicos, enfermeiras, religiosos e a seus próprios parentes. São Paulo: Martins Fontes; 1998.

6. Loureiro A. A velhice, o tempo e a morte: subsídios para possíveis avanços do estudo. Brasília: Editora Universidade de Brasília; 2000.

7. Fuks B. Freud e a cultura. Rio de Janeiro: Jorge Zahar; 2003.

8. Beauvoir S. A velhice I: a realidade incômoda. São Paulo: DIFEL; 1976.

9. Salvarezza L. Fausto MSV. A propósito de la construcción del imaginário social sobre la vejez. In: Salvarezza L. La vejez: uma mirada gerontológica actual. Buenos Aires: Paidós; 2005.

10. Bromberg MH. A Psicoterapia em situações de perdas e luto. Campinas: Editora Livro Pleno; 2000.
11. Néri AL. Contribuições da Psicologia ao estudo no campo da velhice. RBCEH 2004 jan/jun: 1(1): 69-80.

12. Barbieri N. Trabalho com velhos : algumas reflexões iniciais. Pulsional : Revista de psicanálise 2003 set; 16(173): 18-24.

13. Mucida A. O sujeito não envelhece : psicanálise e velhice. Belo Horizonte: Autêntica; 2006.

14. Picabia A, Antequera-Jurado R. La muerte y el morir em el anciano. In: Salvarezza L. La vejez: uma mirada gerontológica actual. Buenos Aires: Paidós; 2005.

15. Freud S. Luto e melancolia : a história do movimento psicanalítico, artigos sobre a metapsicologia e outros trabalhos 1914-1916. Rio de Janeiro: Imago; 1915/2006. v. 14

16. Freud S. Ansiedade, dor e luto: um estudo autobiográfico, inibições, sintomas e ansiedade, análise leiga e outros trabalho 1925-. Rio de Janeiro: Imago; 1925/2006. v.20

17. Arraes AK, Viana TC. O luto na obra freudiana: um afeto normal. Pulsional - Rev Psicanálise 2003 set; 173(16): 7-17.

18. Arraes AK, Viana TC. Afeto e dor: faces do luto na obra freudiana. Rede dos estados gerais $\mathrm{da}$ Psicanálise. 2007 [ Acesso em 6 dez 2007]. Disponível em: < http:// www.estadosgerais.org/encontro/ afeto_e_dor.shtml >.

19. Freud S. Sobre a transitoriedade: a história do movimento psicanalítico, artigos sobre a metapsicologia e outros trabalhos 1914-1916. Rio de Janeiro: Imago; 1916/2006. v.14

20. Frumi C, Celich K. O olhar do idoso frente ao envelhecimento è à morte. RBCEH 2006 jul/ dez;3(2): 92-100. 